\title{
THE EFFECT OF TWO SECOND AND SIXTEEN SECOND AVERAGING ON PULSE OXIMETRY MEASUREMENTS IN THE DELIVERY ROOM (DR)
}

\author{
J.A. Dawson ${ }^{1,2}$, A. Saraswat ${ }^{3}$, L. Simionato ${ }^{3}$, M. Thio ${ }^{1}$, P.G. Davis ${ }^{1,2,3}$ \\ ${ }^{I}$ Neonatal Services, The Royal Women's Hospital, ${ }^{2}$ Murdoch Childrens Research Institute, ${ }^{3}$ University of \\ Melbourne, Melbourne, VIC, Australia
}

Background: Pulse oximetry is used in the delivery room (DR) to measure $\mathrm{SpO}_{2}$ and $\mathrm{HR}$. A short averaging time (2s) has been proposed as the best method for measuring PO data in the DR.

Aim: We aimed to compare simultaneous $\mathrm{SpO}_{2}$ and $\mathrm{HR}$ measurements from pulse oximeter (POs) set to either 2 or 16 second averaging.

Method: Infants born following elective caesarean section were studied. Two Masimo SET Radical POs set to either $2 \mathrm{~s}$ or $16 \mathrm{~s}$ averaging were applied, one to each foot. Simultaneous $\mathrm{SpO}_{2}$ and $\mathrm{HR}$ measurements were collected for 3 to 5 mins. Bland Altman analysis was used to determine levels of agreement between measurements obtained with the different averaging times.

Results: 31 infants were studied; mean(SD) birth weight 3480(473) g, gestational age 39(1) weeks; median(IQR) Apgar scores 9(8-9) and 9(9-10) at 1 and 5 mins, respectively. There was less fluctuation in $\mathrm{SpO}_{2}$ and $\mathrm{HR}$ using 16s averaging.(Figure) The mean difference between $2 \mathrm{~s}$ and $16 \mathrm{~s}$ averaging $\mathrm{SpO}_{2}$ measurements was -1.04 (CI -1.6 to -0.47$) \%$; for HR the mean difference between $2 \mathrm{~s}$ and $16 \mathrm{~s}$ averaging was -0.30 (CI -1.5 to 0.9$)$ beats per minute.

Conclusions: Overall there was excellent agreement between the POs using different averaging times. There may be an advantage in using longer averaging which provides clinicians with more stable data on which to base decisions.
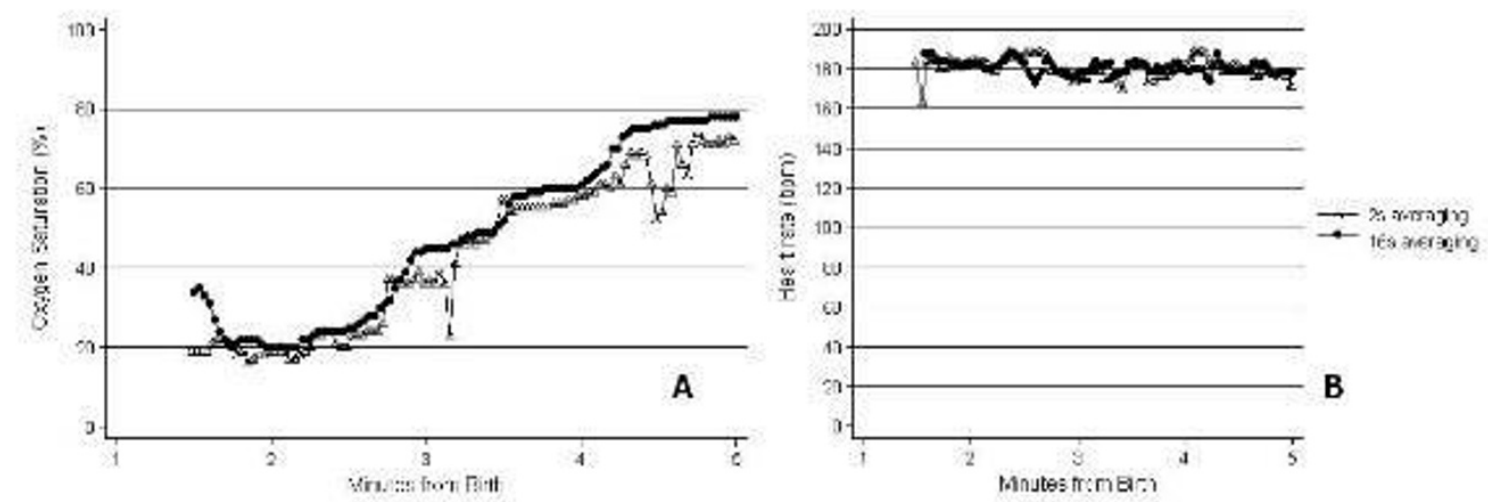

Figure shows $\mathrm{SpO}_{2}(\mathrm{~A})$ and $\mathrm{HR}(\mathrm{B})$ measurements from a study infant born at term who did not receive interventions in the $D R$

[Figure] 